\title{
Sürtünme Karıștırma İşleminin Eklemeli İmalat Yöntemi ile Üretilen AlSi10Mg Alaşımının Tribolojik Özelliklerine Etkisi
}

\author{
Hüccet Kahramanzade ${ }^{1 *}$, Yaşar Sert ${ }^{2}$, Tevfik Küçükömeroğlu ${ }^{3}$ \\ 1*Karadeniz Teknik Üniversite, Mühendislik Fakültesi, Makine Mühendisliği Bölümü, Trabzon, Türkiye, (ORCID ID 0000-0002-9078-1933), \\ h.kahramanzade@ktu.edu.tr \\ 2*Karadeniz Teknik Üniversite, Mühendislik Fakültesi, Makine Mühendisliği Bölümü, Trabzon, Türkiye, (ORCID ID 0000-0001-7742-0335), yasarsert@ktu.edu.tr \\ 3*Karadeniz Teknik Üniversite, Mühendislik Fakültesi, Makine Mühendisliği Bölümü, Trabzon, Türkiye, (ORCID ID 0000-0002-4392-9966), tkomer@ktu.edu.tr
}

(1st International Conference on Applied Engineering and Natural Sciences ICAENS 2021, November 1-3, 2021)

(DOI: $10.31590 /$ ejosat.1013345)

ATIF/REFERENCE: Kahramanzade, H., Sert, Y. \& Küçükömeroğlu, T. (2021). Sürtünme Karıştırma İşleminin Eklemeli İmalat Yöntemi ile Üretilen AlSi10Mg Alaşımının Tribolojik Özelliklerine Etkisi. Avrupa Bilim ve Teknoloji Dergisi, (28), 1159-1166.

\section{$\ddot{O} z$}

Eklemeli imalat yöntemi son yıllarda sıklıkla kullanılmaya başlayan imalat yöntemlerinden biri olarak göze çarpmaktadır. Bu üretim teknolojisi çelik, titanyum, kobalt, bakır ve nikel alaşımlarının yanı sıra Al-Si alaşımlarının üretiminde yaygın bir şekilde kullanılmaktadır. Al-Si alaşımlarııın arasında $\mathrm{Al}-\mathrm{Si} 10 \mathrm{Mg}$ alaşımı yüksek mekanik ve korozyon dayanımı özellikleri ile ön plana çıkmaktadır. Günümüzde, AlSi10Mg alaşımları otomotiv ve havacılık endüstrisinde yaygın bir şekilde kullanılmaktadır. Söz konusu alaşımların uygulama alanlarında kullanım performansını geliştirmek adına bazı tane inceltme amaçlı yöntemler ön plana çıkmıştır. Bu yöntemler arasında, sürtünme karıştırma kaynağından türetilen sürtünme karıştırma işlemi, tane inceltme ve aşırı plastik deformasyon yöntemi olarak göze çarpmaktadır. Bu çalışmada sürtünme karıştırma işleminin (SKİ) eklemeli imalat yöntemiyle üretilen $\mathrm{AlSi} 10 \mathrm{Mg}$ alaşımının mikro yapı, sertlik ve aşınma özelliklerine etkilerinin belirlenmesi amaçlanmaktadır. Bu amaç doğrultusunda, eklemeli imalat yöntemiyle üretilen AlSi10Mg alaşımlarının yüzeyine $1200 \mathrm{dev} / \mathrm{dk}$ takım dönme hızı, $40 \mathrm{~mm} / \mathrm{dk}$ takım ilerleme hızı, $6000 \mathrm{~N}$ takım baskı kuvveti ve $2^{\circ}$ takım açısı ile SKİ gerçekleştirilmiştir. Numunelerin yapısal analizleri, sertlik ve aşınma özellikleri sırasıyla optik mikroskop, taramalı elektron mikroskobu, mikro-sertlik test cihazı ve atmosfer ve vakum ortamında olmak üzere bilye disk tipi aşınma test cihazında belirlenmiştir. SKİ sonrasında eklemeli imalattan doğan katmanlı içyapı ortadan kaldırılmış olup daha düzgün bir yapı elde edilmiş̧tir. İşlemsiz numunenin sertliği 104,5 $\mathrm{HV}_{0,01}$ elde edilirken, işlemli numunede bu değer $98,6 \mathrm{HV}_{0,01}$ olarak belirlenmiştir. SKİ'nin alaşımın aşınma performansına olan etkilerine bakıldığında, atmosfer ortamında yaklaşık \% 40 'lık bir iyileşme söz konusudur. Vakum ortamında bu değer yaklaşık \%10 mertebelerindedir. Atmosfer ortamında baskın aşınma mekanizmasının abrazif aşınma olduğu, vakum ortamında ise kütle transferinin etken olduğu görülmektedir.

Anahtar Kelimeler: Eklemeli İmalat, Sürtünme Karıştırma İşlemi, Aşınma, Sertlik, Vakum

\section{Effect of the Friction Stir Processing on Tribological Properties of AlSi10Mg Alloy Produced by Additive Manufacturing Method}

\begin{abstract}
Additive manufacturing method stands out as one of the manufacturing methods that has been used frequently in recent years. This technology is widely used in the manufacture of steel, titanium, cobalt, copper and nickel alloys, as well as Al-Si alloys. Among the Al$\mathrm{Si}$ alloys, the Al-Si10Mg alloy stands out with its high mechanical and corrosion resistance properties. Nowadays, AlSi10Mg alloys are widely used in the automotive and aerospace industries. In order to improve the usage performance of these alloys, some grain refinement methods have come to the fore. Among these methods, friction stir processing derived from friction stir welding, grain refinement and extreme plastic deformation method take attention. In this study, it is aimed to determine the effects of friction stir process (FSP) on microstructure, hardness and wear properties of AlSi10Mg alloy produced by additive manufacturing method. For this goal, FSP was performed on the surface of AlSi10Mg alloys with $1200 \mathrm{rpm}$ tool rotation speed, $40 \mathrm{~mm} / \mathrm{min}$ tool advance speed, $6000 \mathrm{~N}$ tool pressure force and $2^{\circ}$ tool angle. Structural analysis, wear properties and hardness of the samples were determined by scanning electron microscope, optical microscope, micro-hardness tester and ball-disc type wear tester under ambient air and vacuum environment, respectively. After FSP, the stratified microstructure arising from additive manufacturing has been eliminated and a smoother structure has been obtained. While the hardness of the untreated sample was $104.5 \mathrm{HV}_{0.01}$, this value was determined as 98.6 $\mathrm{HV}_{0.01}$ in the treated sample. Considering the effects of FSP on the wear performance of the alloy, there was an improvement of approximately $40 \%$ in the ambient air. In the vacuum environment, this value was around $10 \%$. It was seen that the dominant wear mechanism was abrasive wear in the atmosphere environment, while mass transfer was the factor in the vacuum environment.
\end{abstract}

Keywords: Additive Manufacturing, Friction Stir Process, Wear, Hardness, Vacuum 


\section{Giriş}

Eklemeli imalat yöntemi son yıllarda sıklıkla kullanılmaya başlayan imalat yöntemlerinden biri olarak göze çarpmaktadır. Eklemeli imalat yönteminde, tozları eriterek veya sinterleyerek bir bileşen üretmek için güç kaynağı kullanılmaktadır [1-3]. Bu üretim teknolojisi, hammaddeleri verimli bir şekilde kullanarak tatmin edici geometrik doğruluk sağlar ve bu sayede minimum atık oluşur [4,5]. Bununla birlikte, bu teknoloji ile üretilen parçalar nispeten pürüzsüz bir yüzeye sahip olduklarından, önemli bir son işleme ihtiyaç duyulmadan doğrudan kullanılabilirler [6]. Son yıllarda, çalışmalar özellikle SLM işleme parametrelerinin ve üretilen mikro yapıların optimizasyonu üzerinde yoğunlaşmıştır $[7,8]$. Bu üretim teknolojisi çelik, titanyum, kobalt, bakır ve nikel alaşımlarının yanı sıra Al- Si alaşımlarının üretiminde yaygın bir şekilde kullanılmaktadır [922]. Söz konusu Al-Si alaşımlarının arasında son yıllarda AlSi10Mg alaşımı yüksek mekanik özellikleri ve korozyon dayanımı özellikleri ile ön plana çıkmakta ve eklemeli imalat yöntemiyle de oldukça pürüzsüz bir yüzeye ve herhangi bir yapısal hataya sebebiyet vermeden üretilebilmektedir. Ayrıca AlSi10Mg alaşımları sıcak çatlamaya karşı yüksek dirençleri nedeniyle kaynaklanabilme özelliğine de sahiptir. Bununla birlikte, bu yöntemde lazer ışını yüksek güç ve tarama hızına sahiptir. Söz konusu bu durum, hızlı katılaştırma işlemi sırasında büyük bir sıcaklık gradyanı oluşturmasından dolayı üretilen alaşımın yapısında gözenekler, inklüzyonlar ve çatlaklar gibi katılaşma kusurları oluşabilmektedir. Bu nedenle alaşımların oda sıcaklığında düşük süneklik, yorulma ve aşınma ömrü gibi olumsuzluklar sergilemektedirler [23]. Katılaşma kusurlarını ortadan kaldırmak ve eklemeli imalatla üretilen AlSi10Mg alaşımının sünekliğini arttırmak için ısıl işlem ve sıcak izostatik presleme (HIP) teknolojileri kullanılmaktadır. Günümüzde eklemeli imalat yöntemiyle yaklaşık $0,02 \mathrm{~m}^{3}$ hacimli numuneler üretilebilmektedir. Söz konusu alaşımın endüstriyel uygulamasını yaygınlaştırmak amacıyla daha büyük parçalar üretebilmek için farklı birleştirme teknikleri mevcuttur. Günümüzde, çok sayıda malzeme türünün birleştirilmesi için kullanılan en yaygın yöntemlerden biri Sürtünme Karıştırma Kaynağıdır. Son on yılda, sürtünme karıştırma kaynağı özellikle Al alaşımlarının birleştirilmesi konusunda mükemmel bir kaynak kalitesi sunmuştur. Ayrıca söz konusu Al alaşımlarının uygulama alanlarında kullanım performansını geliştirmek adına bazı tane inceltme amaçlı yöntemler ön plana çıkmıştır. $\mathrm{Bu}$ yöntemler arasında, son zamanlarda sürtünme karıştırma kaynağından türetilen sürtünme karıştırma işlemi, tane inceltme ve aşırı plastik deformasyon yöntemi olarak kullanılmaktadır. $\mathrm{Bu}$ yöntemde, iş parçasına istenen rota boyunca hareket eden bir pim ve omuzlu dönen bir karıştırma aleti yerleştirilmekte olup, işlenmiş bölge, sürtünme 1sısı ve mekanik karıştırmanın birleşik etkisi altında aşırı plastik deformasyona uğrar ve bu da mikroyapısal arıtma, homojenleştirme ve yoğunlaşmanın aynı anda elde edilmesine yol açar [24]. Chen ve çalışma arkadaşları tarafından gerçekleştirilen bir çalışmada, Mg-8Li-3Al-2Sn alaşımına uygulanan sürtünme karıştırma işlemi neticesinde malzemenin çekme ve akma dayanımının önemli ölçüde arttığı belirlenmiştir [25]. İlgili çalışmada, oluşan dubleks fazlı matriste $\alpha-\mathrm{Mg}$ fazının en sert faz olarak deformasyon kuvvetini taşımakta olduğu, sürtünme karıştırma işlemi sayesinde yapıda bulunan $\alpha-\mathrm{Mg}$ tanelerinin boyutunun azaltıldığı bunun da mukavemet artışında payı olduğu tespit edilmiştir. Sürtünme karıştırma işleminin Mg-Al-Zn alaşımının mekanik özelliklerine etkilerinin incelendiği bir çalışmada, yapıdaki Mg17A112 intermetalik fazın çözünerek ultra ince alt tanelerin oluştuğu ve tane boyutu incelmesinin işlem sonrasındaki mukavemet ve süneklik özelliklerinin iyileştirilmesinde rol oynadığı vurgulanmıştır. İlgili çalışmada, söz konusu alaşımın akma dayanımı $\% 42$, çekme dayanımı $\% 80$, süneklik ise $\% 350$ oranında artırılmıştır. Mukavemet değerlerindeki bu artışın, dinamik yeniden kristalizasyonun neden olduğu tane incelmesi sayesinde artan tane sınırı sertleşmesi ile elde edildiği vurgulanmıştır [26]. Literatürdeki verilen söz konusu çalışmalardan da anlaşılacağı üzere, sürtünme karıştırma işlemi uygulanan malzemelerin sertlik, mekanik, sürtünme ve aşınma özellikleri işlemsiz malzemeye oranla iyileştirilmiştir. Bununla birlikte literatürde, bu çalışmada da ana malzeme olarak kullanılması planlanan SLM ile üretilmiş AlSi10Mg alaşımına sürtünme karıştırma işleminin uygulandığı ve alaşımın mikro yapı ve mekanik özelliklerine olacak muhtemel etkilerin belirlendiği çalışmalar sınırlı sayıda olsa da mevcuttur. Yang ve çalışma arkadaşlarının yapmış oldukları sürtünme karıştırma işleminin SLM-AlSi10Mg alaşımının yapısal ve mekanik özelliklerine etkileri konusundaki incelemelerinde, sürtünme karıştırma işleminin, söz konusu alaşım yüzeyinde oluşan gözenekleri ortadan kaldırdığı, daha önce de belirtmiş olduğumuz gibi yapıyı homojen ve daha yoğun hale getirdiği tespit edilmiştir. Alaşımın yapısındaki Si parçacıkları ve dislokasyon yapısı, mukavemet değerlerini önemli ölçüde etkilediği vurgulanmıştır. Geleneksel ısıl işlem yöntemleriyle kıyaslandığında, söz konusu alaşıma uygulanan sürtünme karıştırma işlemi mukavemet değerlerini artırırken, iyi süneklik özelliği elde etme konusunda da başarılı bir işlem olarak belirlenmiştir [27]. Söz konusu tespitler literatürde yapılmış olup, sürtünme karıştırma işleminin eklemeli imalatla üretilen AlSi10Mg alaşımlarının sürtünme ve aşınma performanslarına etkisi ile ilgili sistematik çalışma eksikliği göze çarpmaktadır. Bu bilgiler ışığında söz konusu eklemeli imalat teknolojisinin, uzay havacılığında kullanılan alaşımların üretiminde kullanılmasının yakın gelecekteki popüler araştırma konularından biri olacağ1 öngörülmektedir. Sürtünme karıştırma işleminin de AlSi10Mg alaşımlarının yapısal ve mekanik özelliğini geliştirdiği vurgusu da yapılmışken, bu işlem uygulanmış alaşımların vakum ortamında (havadan arındırılmış) aşınma performansının incelenmesi gerekliliği ortaya çıkmıştır. Dolayısıyla, çalışmada sürtünme karıştırma işleminin eklemeli imalat yöntemiyle üretilen $\mathrm{AlSi} 10 \mathrm{Mg}$ alaşımının mikro yapı, sertlik ve hem atmosfer hem de vakum ortamında aşınma özellikleri incelenerek elde edilen bulgular literatüre kazandırılmıştır.

\section{Materyal ve Metot}

\subsection{Malzeme Üretimi}

Bu çalışmada AlSi10Mg alaşımı eklemeli imalat yöntemiyle üretilmiştir. Numunelerin üretiminde kullanılan toz parçacığının boyutu yaklaşık 5 ila $30 \mu \mathrm{m}$ aralığındadır. Bu çalışmada kullanılan tozun toz karakterizasyonu ASTM F3049-14'e uygun olarak tedarik edilerek üretilmiştir. Parçalar $30 \mu \mathrm{m}$ katman kalınlığında ve $150 * 30 * 4 \mathrm{~mm}^{3}$ boyutunda EOS/M 290 marka/model cihazında üretilmiştir. Numunelerin üretimi için kullanılan cihaz Şekil 1'de gösterilmiştir. Numunelerin eklemeli imalat yöntemi ile üretiminde kullanılan parametreler ise Tablo 1'de verilmiştir. Numune üretim işlemi sırasında, oksijen içeriğini \% $\%, 1$ 'den daha az tutmak ve erime işlemi sırasında oksit oluşumunu önlemek için işlemler argon gazı ortamında gerçekleştirilmiştir. Bununla birlikte, üretilen numuneler 2 saat süre ile $300{ }^{\circ} \mathrm{C}$ 'de gerilme giderme işlemine tabi tutulmuştur. Eklemeli imalatla üretilen AlSi10Mg alaşımları Şekil 2'de görülmektedir. 


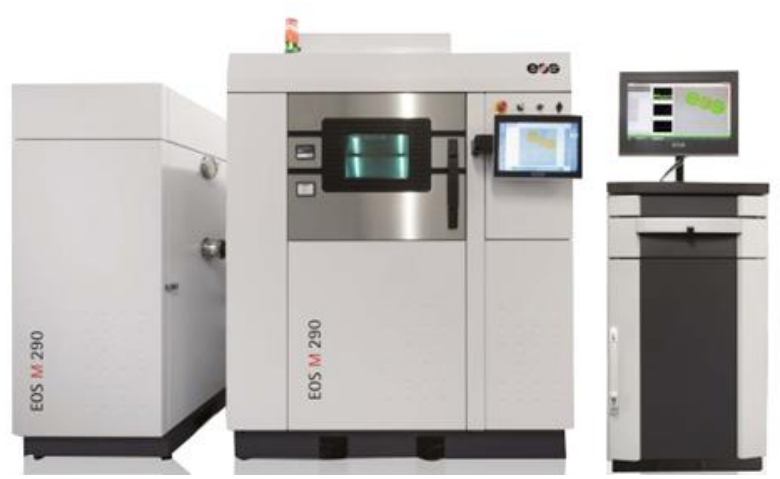

Şekil 1. EOS M 290 marka eklemeli imalat cihazı

Tablo 1. AlSi10Mg numunelerinin eklemeli imalat işlem parametreleri

\begin{tabular}{c|c|c|c}
\hline $\begin{array}{c}\text { Lazer Gücü } \\
(\mathbf{W})\end{array}$ & $\begin{array}{c}\text { Tarama } \\
\text { Hızı }(\mathbf{m m} / \mathbf{s})\end{array}$ & $\begin{array}{c}\text { Katman } \\
\text { Yönlendirme } \\
\text { Açısı }\left(^{(}\right)\end{array}$ & $\begin{array}{c}\text { Katman } \\
\text { Kalınlığı } \\
(\boldsymbol{\mu m})\end{array}$ \\
\hline 370 & 1300 & 67 & 30 \\
\hline
\end{tabular}

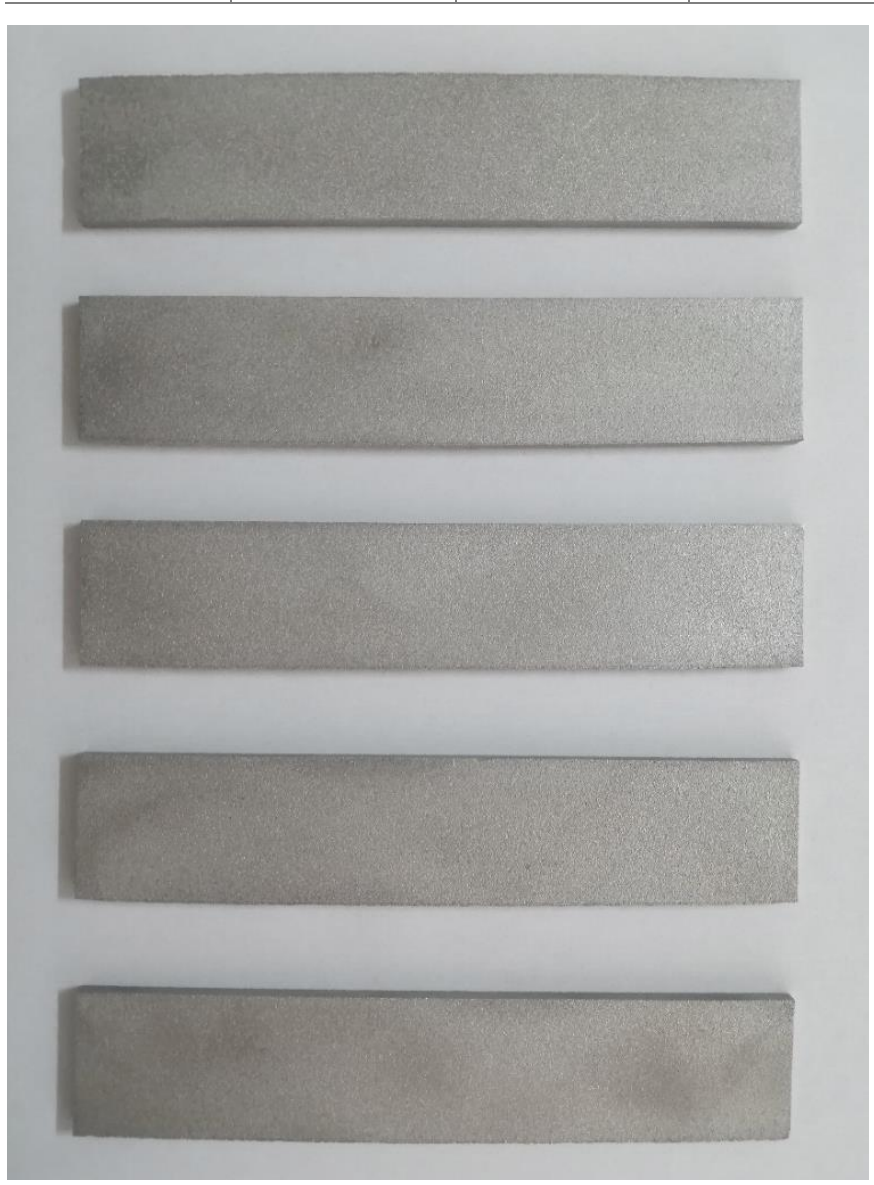

Şekil 2. Eklemeli imalatla üretilen AlSi10Mg alaşımları

\subsection{Sürtünme Karıştırma İşlemi}

Bu çalışmada Sürtünme Karıştırma İşlemi (SKİ) için uygun şekilde geliştirilen Şekil 3 'te görülen üniversal bir freze tezgâhı kullanılmıştır. Tezgâh tablası üzerine takımın uygulayacağı baskı kuvvetinin kontrol edilebilmesi amacıyla hidrolik yükleme düzeneği yerleştirilmiş durumdadır. SKİ uygulanacak olan AlSi10Mg plakalar Şekil 4'te verilen hidrolik düzeneğin üst tablasında bulunan pabuçlar sayesinde sabitlenmektedir.

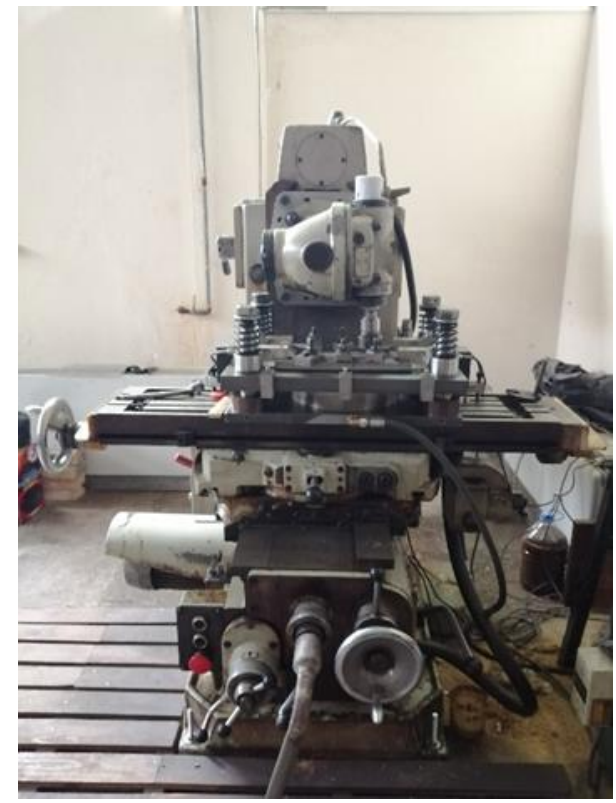

Şekil 3. SKİ düzeneğinin görünümü

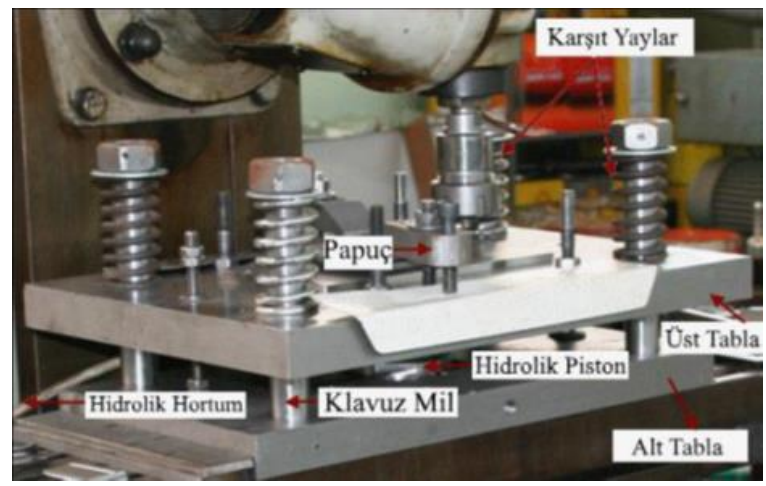

Şekil 4. Hidrolik yükleme düzeneğinin görünümü

Tasarlanan bu hidrolik yükleme düzeneğinde sabit olan alt tabla üzerine yerleştirilen hidrolik piston ve 4 adet kılavuz mil bulunmaktadır. Kılavuz miller üzerine yataklanan haraketli üst tabla takım ekseni doğrultusunda hidrolik piston sayesinde hareket ettirilebilmektedir. Takım baskı kuvvetinin tablanın her bölgesinde dengeli şekilde tutulabilmesi için ise hareketli tabla üzerine 4 adet karşıt yay yerleştirilmiştir. SKİ işlemi için yüksek sıcaklığa ve aşınmaya dayanıklı tungsten karbür (WC) takım kullanılmıştır. SKİ'nde kullanılan parametreler Tablo 2'de verilmiştir.

Tablo 2. Sürtünme karıştırma işlem parametreleri

\begin{tabular}{c|c|c|c}
\hline $\begin{array}{c}\text { Takım } \\
\text { Dönme Hızı } \\
\text { (dev/dk) }\end{array}$ & $\begin{array}{c}\text { Takım } \\
\text { İlerleme } \\
\text { Hızı } \\
(\mathbf{m m} / \mathbf{d k})\end{array}$ & $\begin{array}{c}\text { Takım Baskı } \\
\text { Kuvveti }(\mathbf{N})\end{array}$ & $\begin{array}{c}\text { Takım Açısı } \\
\left(^{\circ}\right)\end{array}$ \\
\hline 1200 & 40 & 6000 & 2 \\
\hline
\end{tabular}

SKİ uygulanmış AlSi10Mg alaşımının görüntüsü Şekil 5'te verilmiştir. Şekilden de görüldüğü üzere, yukarıda belirtilen parametrelerle uygulanan SKİ neticesinde, alaşım yüzeyinde homojen ve başarılı bir karışma yüzeyi elde edilmiştir. Bu görsel üzerinden, SKI'nin başarılı bir şekilde uygulandığ söylenebilmektedir. 


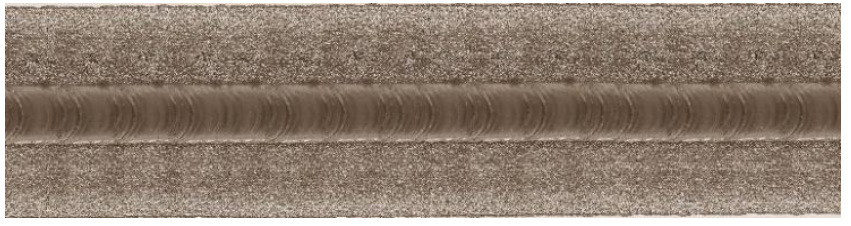

Şekil 5. SKİ uygulanmış AlSi10Mg alaşımı

\subsection{Numunelerin Hazırlanması}

SKİ gerçekleştirildikten sonra numunelerin işlem bölgelerinden Şekil 6'da örnek olarak gösterildiği gibi içyap1, sertlik ve aşınma özelliklerinin incelenmesi amacıyla numuneler çıkarılmıştır.

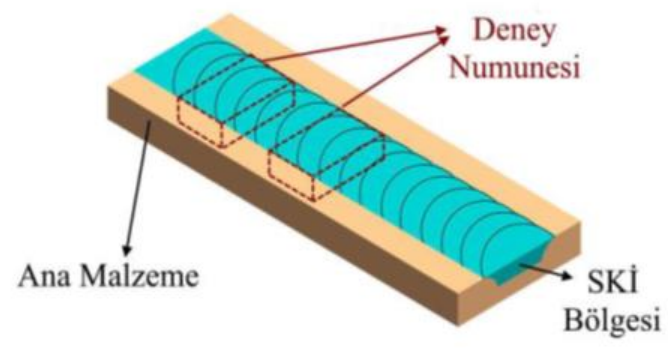

Şekil 6. İşlem uygulanmış AlSi10Mg plakadan çıkarılan deney numunelerinin konumlar

\subsection{Yapısal, Sertlik ve Tribolojik Analizler}

İşlemsiz ve SKİ numunelerinin faz analizleri Panalytical Empyrean X-1şını kırınım ölçer (XRD) ve EDAX enerji dağılımlı X-1şını spektroskopisi (EDS) kullanılarak gerçekleştirilmiştir. XRD ölçümlerinde $\lambda=1,54059 \AA$ dalga boyuna sahip $\mathrm{Cu}-\mathrm{K} \alpha$ ışınımı kullanılmış ve elde edilen sonuçlar The International Centre for Diffraction Data (ICDD) standart kartları ile karşılaştırılarak oluşan fazların kimyasal kompozisyonları tespit edilmiştir.

Numunelerin içyapısının analizi için, manyetik karıştırıcı yardımıyla hazırlanan Keller ayracı $\left(2,5 \mathrm{~mL} \mathrm{HNO}_{3}, 1,5 \mathrm{~mL} \mathrm{HCl}\right.$, $1 \mathrm{~mL} \mathrm{HF}$ ve $35 \mathrm{~mL} \mathrm{H} \mathrm{H}_{2} \mathrm{O}$ ) ile dağlama işlemi gerçekleştirilmiştir. Metalografik olarak hazırlanan numunelerin yapısal analizleri ZEISS marka optik mikroskop (OM) ve taramalı elektron mikroskobu (SEM) ile gerçekleştirilmiştir. Numunelerin mikro sertlik değerlerinin belirlenmesi amacıyla Struers Duramin 3 marka mikro sertlik cihazı kullanılmıştır. Mikro sertlik ölçümleri 10 gr yük altında $10 \mathrm{~s}$ yükleme süresinde gerçekleştirilmiştir. Her bir numuneden birbirini etkilemeyecek mesafede en az beş ölçüm yapılmış ve bu değerlerin ortalaması alınmıştır. Numunelerin tribolojik özelliklerinin belirlenmesi amacıyla deneyler, DUCOM marka bilgisayar kontrollü aşınma cihazında 1 N'luk normal yük altında ve $10 \mathrm{~mm}$ iz çapında, atmosfer ortamı ve vakum şartlarında bilye disk aşınma test yöntemi kullanılarak gerçekleştirilmiştir. Deneyler sırasında karşı yüzey olarak $6 \mathrm{~mm}$ çapl $\mathrm{Al}_{2} \mathrm{O}_{3}$ seramik bilye kullanılmıştır. Yapılan testler sonunda her bir numunede meydana gelen aşınma miktarının hesaplanmasında Archard aşınma eşitliği olarak bilinen bağıntıdan yararlanılmıştır.

$$
k=Q / W L
$$

Burada Q kaybedilen toplam malzeme hacmini $\left(\mathrm{mm}^{3}\right), \mathrm{L}$ toplam kayma mesafesini $(\mathrm{m})$ ve $\mathrm{W}$ uygulanan normal yükü $(\mathrm{N})$ göstermektedir. $\mathrm{k}$ değeri ise aşınma oranını $\left(\mathrm{mm}^{3} / \mathrm{Nm}\right)$ ifade etmektedir.
İşlemsiz ve SKİ uygulanmış numuneler üzerinde gerçekleştirilmiş sürtünme-aşınma deneyleri neticesinde elde edilen numunelerin aşınma izleri Nanofocus marka temassız optik profilometre yardımıyla incelenmiş, SKI'nin AlSi10Mg malzemelerinin aşınma özelliklerine etkileri sistematik olarak belirlenmiştir. Oluşan aşınma mekanizmaları ise aşınma yüzeylerinin SEM ve EDS incelenmesiyle karakterize edilmiştir.

\section{Araştırma Sonuçları ve Tartışma}

İşlemsiz ve SKİ uygulanan numunelerin XRD grafiği Şekil 7'de verilmiştir. Şekilde de görüldüğü gibi Al ve Si elementlerine ait pikler XRD sonuçlarından elde edilmiştir. 4 farklı pike ait detaylar ayrıca verilmiştir. Detaylarda verilen piklere bakıldığında, SKİ işlemli malzemeden elde edilen sonuçlarda az da olsa piklerde bir miktarda kayma oluşmuştur. Bu durum ise SKİ işleminden kaynaklı, malzeme içerisinde oluşan çeki iç gerilemelerinin var olduğunu göstermektedir. Söz konusu iç gerilmelerinin varlığının sayısal olarak ortaya konulması amacıyla XRD verilerinin X-Pert High Score yazılımı kullanılarak, Williamson Hall yaklaşımı ile değerlendirilmesi neticesinde yukarıdaki yorumu doğrular nitelikte değerler elde edilmiştir. İşlemsiz AlSi10Mg alaşımında, gerilme giderme işlemi uygulanmasına rağmen, eklemeli imalat üretiminden kaynak 9,6 $\pm 3 \mathrm{MPa}$ değerinde iç gerilme tespit edilmiştir. Bununla birlikte, SKİ'nden sonra AlSi10Mg alaşımının iç gerilme değeri 49,6 \pm 10

MPa olmuştur. Yukarıda belirtilen yaklaşımla elde edilen iç gerilme değerleri, literatürde benzer çalışmalarla uyumlu olmaktadır. Maamoun ve çalışma arkadaşlarının gerçekleştirdikleri bir çalışmada, AlSi10Mg alaşımına SKI uygulandıktan sonra iç gerilmelerinde artış meydana geldiği görülmüştür [28].
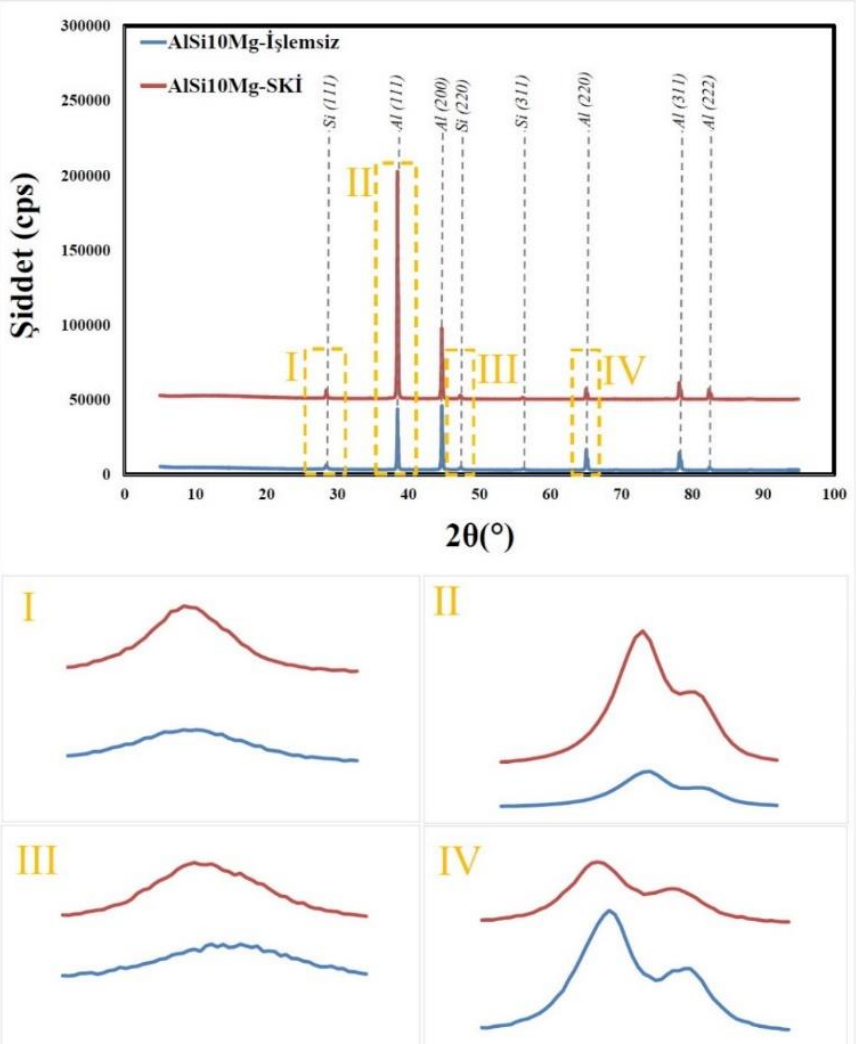

Şekil 7. Numunelerin XRD analizleri 
Şekil 8'de işlemsiz ve SKİ uygulandıktan sonra numunelerin yüzey SEM ve optik mikroskop görüntülerini göstermektedir. İşlemsiz bölgede katmanlı üretim izleri net bir şekilde hem optik hem de SEM görüntülerinden görülmektedir. SKİ sonras1 katmanlı imalat izleri tamamen ortadan kalkmış ve düz bir yapı elde edilmiştir. Bu durum yapının daha düzgün olmasını sağlamak ile birlikte, aşınma deneylerinde oluşacak olan sürtünme katsayısı değerlerini ciddi şekilde etkileyecektir. Dağlama sonrası elde edilen SEM görüntüsünden de anlaşıldığı gibi, dağlama esnasında katmanlar arasında yapılar bozulmuştur. SKİ işlemi sonrası bu dezavantajından ortadan kalktığı görülmektedir.

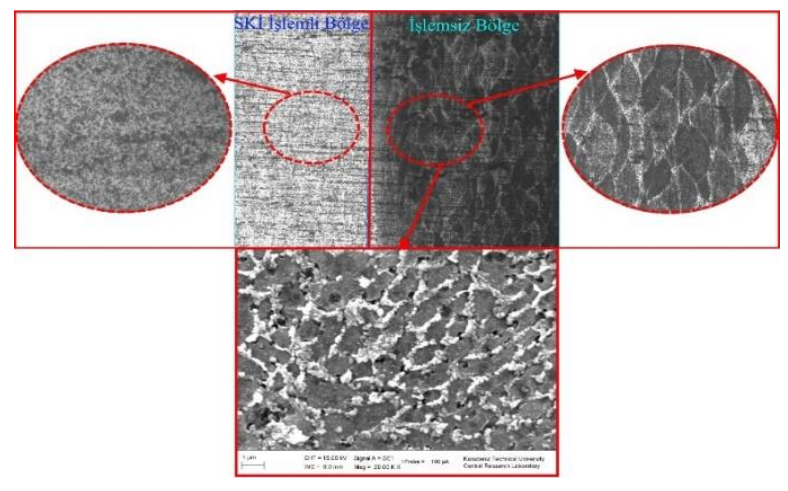

Şekil 8. Numunelerin yüzey görüntüleri

Şekil 9'da SKİ uygulanan numunelere ait kesitteki yap1 gösterilmiştir. Şekilden de görüldüğü gibi, işlemli bölge içerinde malzeme düz bir yapıya sahiptir. Fakat SKİ uygulanmamış bölgede eklemeli imalat katmanları malzemenin yapısında net bir şekilde görülmektedir. Takımın dönme ve malzeme yüzeyinde hareketi ile birlikte takımın altı kısmında kalan bölgelerde içyapı değişmiştir. Takımın alanı dışında kalan bölgelerde eklemeli imalat katmanları görülmektedir.

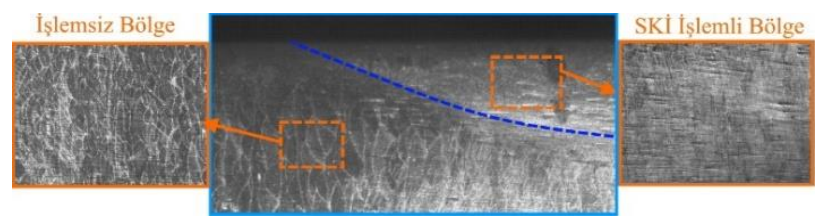

Şekil 9. İşlemsiz ve SKİ bölgelerinin kesin görünümü

Gerçekleştirilen mikro sertlik testlerinde, işlemsiz malzemede $104,5 \mathrm{HV}_{0,01}$ olarak ölçülen sertlik değerinin, işlem uygulanan numunede $98,6 \mathrm{HV}_{0,01}$ olduğu tespit edilmiştir. SKI sonrası oluşan farkın sebebi ise, aşırı plastik deformasyon işlemi esnasında malzemenin 1sınıp tekrar soğuması sonucunda içyapıda oluşan değişikliklerden kaynaklanmaktadır. SKİ'den sonra alaşımın sertlik değerinde görülen azalma literatürdeki çalışmalarla uyumludur [28, 29]. İlgili çalışmalarda, sertlikte söz konusu bu düşüşün sebebi, SKİ sırasında AlSi10Mg eklemeli imalat numuneleri için karakteristik olan çok ince Si faz ağının çözünmesi olarak vurgulanmıştır [28]. İlk Si ağının çözülmesinin ardından yapıdaki Si çökeltilerinin büyümesi, SKİden sonra sertlikteki düşüşe neden olmaktadır.

Yapılan aşınma deneyleri boyunca kaydedilen sürtünme katsayısı değerleri Şekil 10'da verilmiştir. Buna göre, yükten bağımsız olarak atmosfer ortamında işlemsiz numune SKİ uygulanmış numuneye nazaran daha yüksek sürtünme katsayısına sahiptir. Bunun sebebi ise, SKİ sonrası malzeme içyapısında oluşan karışma sonucunda, eklemeli imalat yönteminde gelen karakteristik katmanlı yapının kaybolması ile ilişkilidir. Vakum ortamında ise SKİ uygulanmış numune işlemsiz numuneye nazaran daha yüksek sürtünme katsayına sahiptir. Bu durum ise, yapılan işlem sonrası meydana gelen sertlik değerindeki düşüş ile açıklanabilmektedir. Atmosfer ortamında $\mathrm{Al}$ elementi, oksijen ile reaksiyona geçip seramik $\mathrm{Al}_{2} \mathrm{O}_{3}$ bileşeninin oluşması ile birlikte daha sert bir yapı üzerinde aşınma oluşmaktadır. Fakat vakum ortamında oksijenin bulunmadığı için herhangi bir reaksiyon söz konusu değildir. SKİ uygulanmış numunelerin sertlik değerlerinin düşük olmasından dolayı aşınma yolu boyunda daha çok sıvanmaların oluştuğu, bunun neticesinde ise işlemsiz numuneye nazaran daha yüksek sürtüne katsayısı meydana geldiği görülmüştür. Oluşan kütle transferi esnasında malzeme ile karşı yüzey arasında mikro kaynakların oluşması ve kütle transferinin gerçekleşme sürtünme katsayısını etkilemektedir.

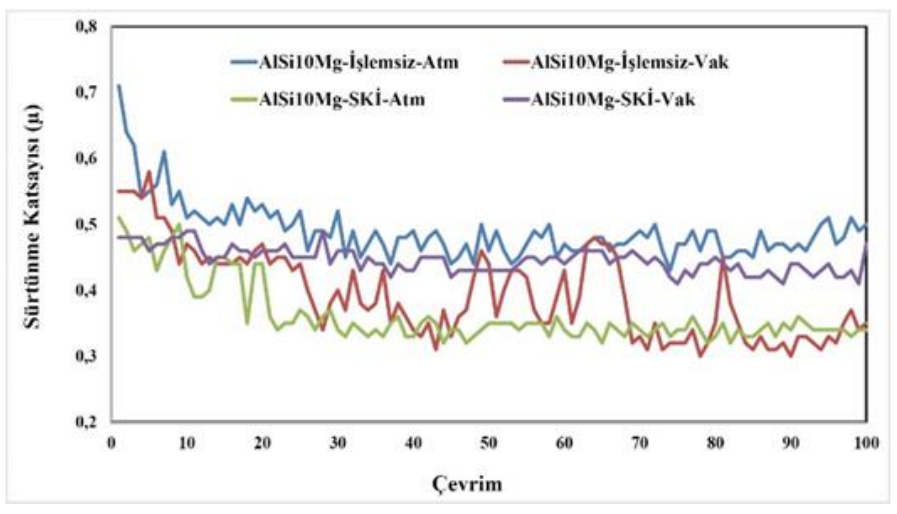

Şekil 10. İşlemsiz ve SKİ uygulanmış numunelerin 2 farklı ortamdaki sürtünme katsayısı değerleri

$1 \mathrm{~N}$ normal yük kullanılarak gerçekleştirilen aşınma deneyleri neticesinde hesaplanan aşınma oranları numunelerin sertlik değerleri ile birlikte Şekil 11'de gösterilmiştir. Buna göre yükten bağımsız olarak en büyük aşınma oranları hem atmosfer hem de vakum ortamında işlemsiz numunelere ait olduğu belirlenmiş. $1 \mathrm{~N}$ yük altında en iyi aşınma performansını, SKI uygulanmış numunenin atmosfer ortamından elde edildiği görülmektedir. Aşınma oranlarının vakum ortamında atmosfere nazaran arttığı görülmektedir. $\mathrm{Bu}$ durum ise vakum ortamında oksijenden arındırılmış ortam sebebiyle, $\mathrm{Al}_{2} \mathrm{O}_{3}$ 'ün oluşmaması ile açılanabilmektedir. Atmosfer ortamında gerçekleştirilen deneylerde, numune yüzeyi sürekli oksijen ile temasta olduğu için, doğal olarak Al alaşımlarının yüzeyinde bulunan oksit tabakası yenilenerek aşınma oranını ciddi anlamda etkilemektedir.

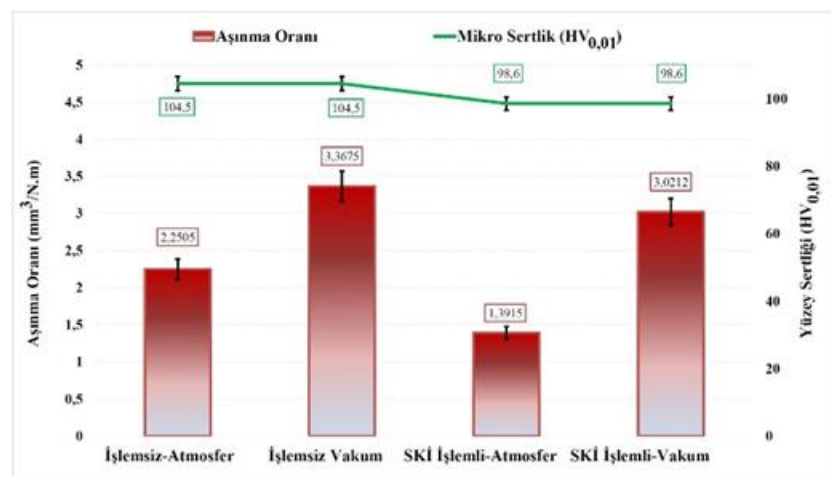

Şekil 11. Numunelerin sertlik ve her iki ortamdaki aşınma oranlart

Aşınma deneyleri sonrası numuneler yüzeyinde meydana gelen aşınma hacminin belirlenmesi için optik profilometre analizleri gerçekleştirilmiş olup, bu analizden elde edilen görüntüler Şekil 12'de verilmiştir. Şekilden de görüldüğü üzere, atmosfer ortamında yapılan deney numunelerinin aşınma 
izlerinde parçacıklar görülmektedir. $\mathrm{Bu}$ parçacıklar $\mathrm{Al}_{2} \mathrm{O}_{3}$ parçacıkları olarak tanımlanabilir. Al elementinin oksitlenmesi ile birlikte oluşan $\mathrm{Al}_{2} \mathrm{O}_{3}$ filmi gevrek bir yapıda olduğu için, parçacıklar halinde kırılarak yüzeyden ayrılmıştır. Fakat vakum ortamında gerçekleştirilen deneylerden elde edilen görüntüler incelendiğinde, büyük oranda kütle transferinin gerçekleştiği görülmektedir. Ayrıca vakum ortamında oluşan aşınma izlerinin daha derin izler olduğu net bir şekilde görülmektedir.

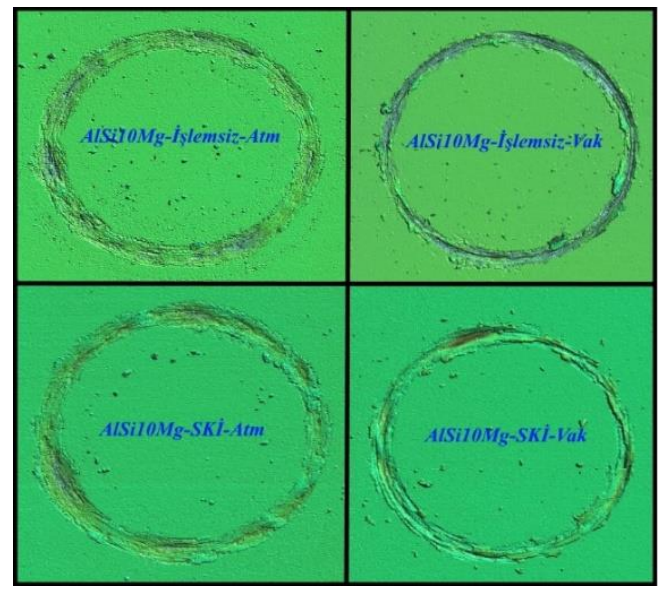

Şekil 12. Numunelerde oluşan aşınma izlerinin optik profilometre görüntüleri

Aşınma deneyleri neticesinde oluşan aşınma mekanizmalarının incelenmesi amacıyla hem işlemsiz hem de SKİ uygulanmış numunelerde oluşan aşınma izleri SEM ve EDS analizleri ile incelenmiştir. Elde edilen SEM görüntüleri Şekil 13 'te verilmiştir. SEM görüntülerinden de görüldüğü gibi, oluşan aşınma iz genişlikleri işlemsiz-atm, işlemsiz-vak, SKİ işlemli-atm ve ASKİ işlemli-vak numuneleri için sırasıyla 476, 280, 410 ve $380 \mu \mathrm{m}$ 'dir. Aşınma iz genişliğinin atmosferde yapılan deneylerde vakum ortamında yapılan deneylere nazaran daha geniş olduğu görülmektedir. $\mathrm{Bu}$ durum, atmosferde $\mathrm{Al}$ parçacıklarının oksijen ile reaksiyona geçip $\mathrm{Al}_{2} \mathrm{O}_{3}$ oluşumundan sonra, aşınma parçacıklarının karşı yüzey ile numune arasına sıkışmasından kaynaklandığı düşünülmektedir. Detaylı SEM görüntüleri incelendiğinde atmosfer ortamında yapılan gerçekleştirilen deneylerde, numuneler üzerinde abrazif aşınma izleri görülmektedir. Ayrıca ince aşınma parçacıklarının da yüzeyde var olması bu durumu kanıtlamaktadır. Partiküllerin karşı yüzey ile numune yüzeyi arasına sıkışması neticesinde abrazif aşınma izleri numune yüzeyinde oluşmaktadır. Vakum ortamında gerçekleştirilen aşınma deneylerinde ise aşınma izlerinin daha derin olduğu ve kütle transferi mekanizması net bir şekilde görülmektedir.

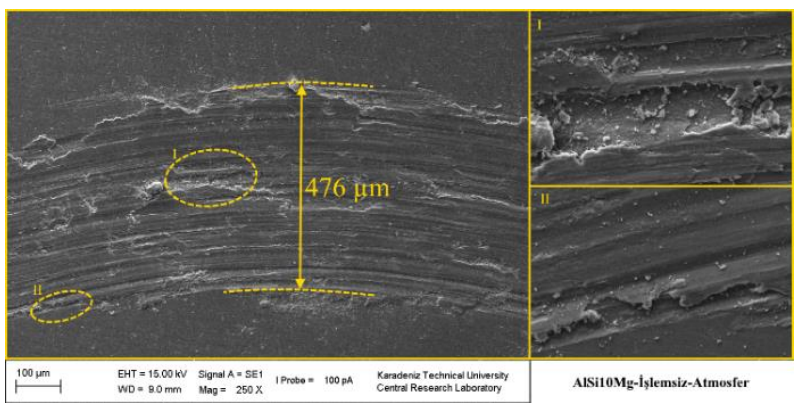

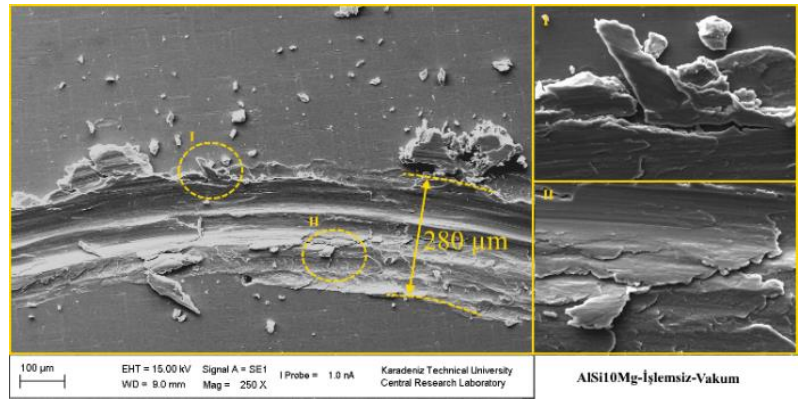
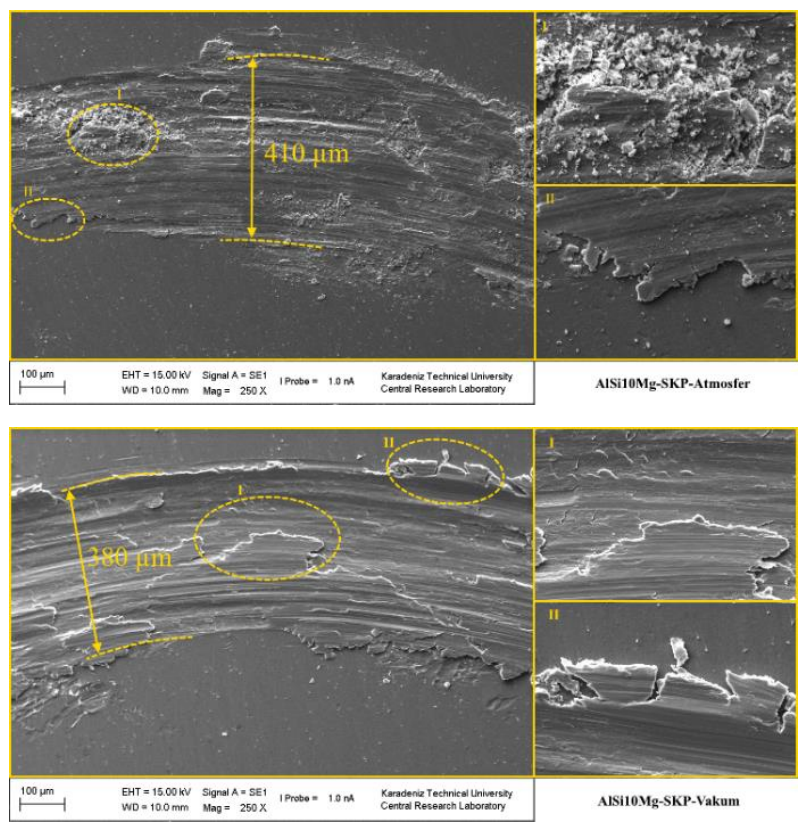

Şekil 13. Aşınma izlerine ait SEM görüntüleri

EDS analizleri, hem aşınma izi içerisinde hem de aşınma izi dışından Map-EDS olarak gerçekleştirilmiştir. EDS analizlerinden elde edilen sonuçlar Tablo 3 'te verilmiştir. Ayrıca Map-EDS analizinden elde edilen element dağılım görüntüleri Şekil 14'te verilmiştir. EDS sonuçlarına bakıldığında, SKİ sonrası malzemede oksijen miktarında çok az bir artış görülmektedir. Bu durum SKİ işlemi sırasında malzemenin ısınması ile birlikte malzeme yapısına oksijenin yerleşmesini göstermektedir. Atmosfer ortamında yapılan aşınma deneyi sonrası, aşınma izi içerisinden yapılan EDS analizlerinde, oksijen miktarının ciddi bir artış gösterdiği görülmektedir. İşlemsiz numunede bu artış $\% 3,34$ 'ten $\% 17,28$ 'e ve SKİ uygulanmış numunede ise bu artışın \%3,84'ten \%18,90'a kadar olduğu görülmektedir. Bu durum ise malzeme yapısında var olan elementleri oksijen ile reaksiyona girmesi neticende oluşan oksit yapılarının var olduğunu göstermektedir. Vakum ortamında yapılan aşınma deneyleri sonrası, hem işlemsiz hem de SKİ uygulanmış numunede aşınma izi içerisinde oksijen miktarında bir düşüş yaşandığ görülmektedir. İşlemsiz malzemelerde oksijen miktarı \%3,34'ten $\% 1,91$ 'e ve SKİ numunesinde \%3,84'ten \%2,73'e kadar düştüğü görülmektedir. Al alaşımlarında, bilindiği gibi malzeme yüzeyinde doğal oksit tabakası oluşmaktadır. Vakum ortamında yapılan aşınma deneyi sonrası bu tabakanın kalkması ile birlikte oksijen miktarında da düşüşlerin meydana gelmesi beklenen bir durumdur. 
Tablo 3. EDS analiz sonuçları

\begin{tabular}{c|c|c|c|c|c|c|c|c}
\hline \multirow{2}{*}{$\begin{array}{c}\text { Eleme } \\
\text { nt }\end{array}$} & \multicolumn{4}{|c|}{ İşlemsiz } & \multicolumn{4}{c}{ SKP İşlemli } \\
\cline { 2 - 9 } & \multicolumn{2}{|c|}{ Atmosfer } & \multicolumn{2}{c|}{ Vakum } & \multicolumn{2}{c}{ Atmosfer } & \multicolumn{2}{c}{ Vakum } \\
\cline { 2 - 8 } & $\mathbf{I} \mathbf{z}$ İçi & $\begin{array}{c}\text { İz } \\
\text { Dışı }\end{array}$ & $\begin{array}{c}\text { İz } \\
\text { İçi }\end{array}$ & $\begin{array}{c}\text { İz } \\
\text { Dıșı }\end{array}$ & $\begin{array}{c}\text { İz } \\
\text { İçi }\end{array}$ & $\begin{array}{c}\text { İz } \\
\text { Dışı }\end{array}$ & $\begin{array}{c}\text { İz } \\
\text { İçi }\end{array}$ & $\begin{array}{c}\text { İz } \\
\text { Dışı }\end{array}$ \\
\hline$A l$ & 73,92 & 85,6 & 87,6 & 85,6 & 72,1 & 84,1 & 86,1 & 84,1 \\
\hline$S i$ & 7,70 & 9,92 & 9,23 & 9,92 & 7,79 & 1,83 & 9,96 & 1,83 \\
\hline$M g$ & 1,10 & 1,10 & 1,18 & 1,10 & 1,12 & 1,15 & 1,17 & 1,15 \\
\hline$O$ & 17,28 & 3,34 & 1,91 & 3,34 & 18,9 & 3,84 & 2,73 & 3,84 \\
\hline
\end{tabular}

Map-EDS analiz görüntülerine bakıldığında, malzeme yüzeyi ve aşınma izi içerisinde oluşan farklılıklar net bir şekilde görülebilmektedir. Malzeme yüzeyi ile atmosfer ortamında yapılan aşınma izi içerisinden alınan görüntüler kıyaslandığında, oksijen miktarının arttığı net bir şekilde görülmektedir. İşlemsiz malzemede sarı renk ile gösterilmiş olan oksijenin yüzeye dağıldı ̆̆ 1 görülmekte, fakat aşınma izi içerisinde alınan görüntülere bakıldığında sarı renk ile gösterilen oksijen elementinin farklı bölgelere biriktiği net bir şekilde görülmektedir. Bu durum, vakum ortamında yapılan aşınma izi içerisinden alınan Map-EDS analizlerinde görülmemektedir.

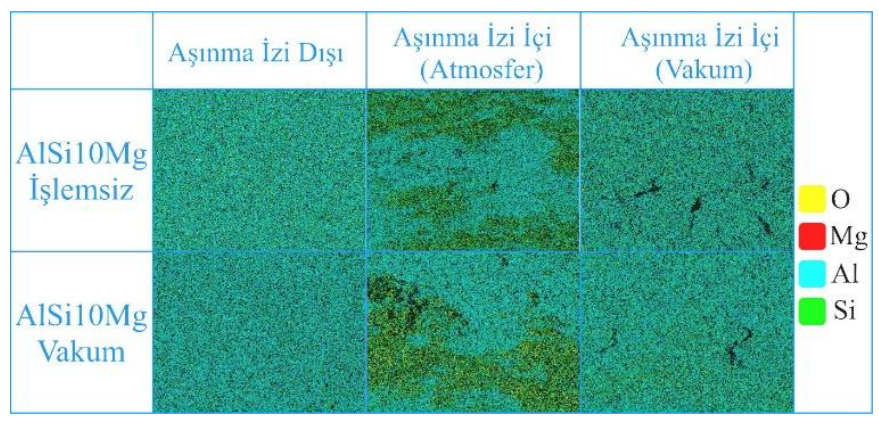

Şekil 14. Map-EDS analizi

\section{Sonuç}

Bu çalışmada, eklemeli imalat yöntemi ile üretilen A1Si10Mg alaşımının yüzeyine $1200 \mathrm{dev} / \mathrm{dk}$ takım dönme hızında, $6000 \mathrm{~N}$ baskı kuvveti ve $2^{\circ}$ takım açısı ile SKİ uygulanmıştır. Uygulanan SKI'nin eklemeli imalatla üretilen AlSi10Mg alaşımlarının yapısal, sertlik ve aşınma özelliklerine etkileri belirlenmiş olup, elde edilen sonuçlar aşağıda verilmiştir.

- SKİ neticesinde eklemeli imalat ile üretilen ALSi10Mg alaşımının karakteristik katmanlı yapısı karıştırma sonucunda düz bir yapı halini almıştır.

-XRD analizinde, yapıda Al ve Si piklerinin baskın olduğu görülmektedir. Bununla birlikte SKİ neticesinde XRD piklerinde bir miktar sağa kayma söz konusudur. Belirlenen bu pik kayması, numunede işlem sonrasında oluşan iç gerilmelere işarettir. İşlemsiz AlSi10Mg alaşımında, gerilme giderme işlemi uygulanmasına rağmen, eklemeli imalat üretiminden kaynaklı 9,6 $\pm 3 \mathrm{MPa}$ değerinde iç gerilme tespit edilmiştir. Bununla birlikte, SKİ'nden sonra AlSi10Mg alaşımının iç gerilme değeri 49,6 \pm 10 $\mathrm{MPa}$ olmuştur.

- İşlemsiz AlSi10Mg alaşımında mikrosertlik değeri 104,5 $\mathrm{HV}_{0,01}$ olarak elde edilirken, işlem uygulanan numunede mikrosertlik değeri 98,6 $\mathrm{HV}_{0,01}$ olarak belirlenmiştir.

- SKİ sayesinde AlSi10Mg alaşımının aşınma performansı hem atmosfer ortamında, hem de vakum ortamında dikkate değer şekilde iyileştirilmiştir. Bununla birlikte, atmosfer ortamında numunelerin aşınma performansları, vakum ortamına nazaran daha yüksek olduğu belirlenmiştir.

- Atmosfer ortamında baskın aşınma mekanizması abrazif aşınma olurken, vakum ortamında kütle transfer mekanizması ön plana çıkmıştır.

\section{Teșekkür}

$\mathrm{Bu}$ çalışma Karadeniz Teknik Üniversitesi Bilimsel Araştırma Projeleri Koordinasyon Birimi tarafından desteklenmiştir. Proje Numaras1: FHD-2020-8827

\section{Kaynakça}

[1] Gibson, I., Rosen, D.W., Stucker, B., Additive Manufacturing Technologies: Rapid Prototyping to Direct Digital Manufacturing, Springer, USA, 2009.

[2] Wong, K.V., Hernandez, A., A review of additive manufacturing, Int. Sch. Res. Netw. 2012: 1-12, (2012).

[3] Frazier, W.E., Metal additive manufacturing: a review. J. Mater. Eng. Perform. 23: 1917-1928, (2014).

[4] ASTM, Standard Terminology for Additive Manufacturing Technologies ASTM International, West Conshohocken, 2012.

[5] Levy, G.N., Schindel, R., Kruth, J.P., Rapid manufacturing and rapid tooling with layer manufacturing (LM) technologies, state of the art and future perspectives. CIRP Ann. Manuf. Technol. 52: 589-609, (2003).

[6] Sallica-Leva, E., Jardini, A.L., Fogagnolo, J.B., Microstructure and mechanical behavior of porous $\mathrm{Ti}-6 \mathrm{Al}-$ $4 \mathrm{~V}$ parts obtained by selective laser melting. J. Mech. Behav. Biomed. Mater. 26: 98-108, (2013).

[7] Gu, D.D., Meiners, W., Wissenbach, K., Poprawe, R., Laser additive manufacturing of metallic components: materials, processes and mechanisms. Int. Mater. Rev. 57: 125-131, (2012).

[8] Murr, L.E., Quinones, S.A., Gaytan, S.M., Lopez, M.I., Rodela, A., Martinez, E.Y., Hernandez, D.H., Martinez, E., Medina, F., Wicker, R.B., Microstructure and mechanical behavior of $\mathrm{Ti}-6 \mathrm{Al}-4 \mathrm{~V}$ produced by rapid-layer manufacturing, for biomedical applications. J. Mech. Behav. Biomed. Mater. 2: 20-32, (2009).

[9] Martin, J.H., Yahata, B.D., Hundley, J.M., Mayer, J.A., Schaedler, T.A., Pollock, T.M., 3D printing of high-strength aluminium alloys, Nature, 549: 365-369, (2017).

[10] Le, K.Q., Tang, C., Wong, C.H., A Study on the Influence of Scanning Strategies on the Levelness of the Melt Track in Selective Laser Melting Process of Stainless Steel Powder, JOM. 70: 2082-2087, (2018).

[11] AlMangour, B., Grzesiak, D., Yang, J.M., Rapid fabrication of bulk-form TiB2/316L stainless steel nanocomposites with novel reinforcement architecture and improved performance by selective laser melting J. Alloys Compd. 680: 480-493, (2016).

[12] Chou, R., Milligan, J., Paliwal, M., Brochu, M., Additive Manufacturing of Al-12Si Alloy Via Pulsed Selective Laser Melting, JOM. 67: 590-596, (2015).

[13] Attar, H., Haghighi, S.E., Kent, D., Wu, X.H., Dargusch, M.S., Comparative study of commercially pure titanium produced by laser engineered net shaping, selective laser melting and casting processes, Mater. Sci. Eng. A 705: 385393, (2017). 
[14] Vastola, G., Zhang, G., Pei, Q.X., Zhang, Y.W., Modeling the microstructure evolution during additive manufacturing of ti6al4v: a comparison between electron beam melting and selective laser melting. JOM, 68: 1370-1375, (2016).

[15] Li, J.Y., Chen, C.J., Liao, J.K., Liu, L., Ye, X.H., Lin, S.Y., Ye, J. T., J. Prosthet. Dent. 118: 69, (2017).

[16] Song, C.H., Zhang, M.K., Yang, Y.Q., Wang, D., Yu, J.K., Morphology and properties of CoCrMo parts fabricated by selective laser melting, Mater. Sci. Eng. A 713: 206-213, (2018).

[17] Ventura, A.P., Wade, C.A., Pawlikowski, G., Bayes, M., Watanabe, M., Misiolek, W.Z., The Effect of Aging on the Microstructure of Selective Laser Melted Cu-Ni-Si, Metall. Mater. Trans. A 48: 6070-6082, (2017).

[18] Ikeshoji, T.T., Nakamura, K., Yonehara, M., Imai, K., Kyogoku, H.,Selective Laser Melting of Pure Copper JOM. 70: 396-400, (2018).

[19] Covarrubias, E.E., Eshraghi, M., Effect of Build Angle on Surface Properties of Nickel Superalloys Processed by Selective Laser Melting, JOM. 70: 336-342, (2018).

[20] Saedi, S., Moghaddam, N.S., Amerinatanzi, A., Elahinia, M., Karaca, H.E., On the effects of selective laser melting process parameters on microstructure and thermomechanical response of Ni-rich NiTi, Acta Mater. 144: 552-560, (2018).

[21] Asgari, H., Baxter, C., Hosseinkhani, K., Mohammadi, M., On microstructure and mechanical properties of additively manufactured AlSi10Mg_200C using recycled powder, Mater. Sci. Eng. A 707: 148-158, (2017).

[22] Kempen, K., Thijs, L., Humbeeck, J.V., Kruth, J.P., Mechanical Properties of AlSi10Mg Produced by Selective Laser Melting, Phys. Proc. 39: 439-446, (2012).

[23] Tang, M., Pistorius, P.C., Oxides, porosity and fatigue performance of AlSi10Mg parts produced by selective laser melting, Int. J. Fatigue, 94: 192-201, (2017).

[24] Yang, K., Li, W.Y., Huang, C.J., Yang, X.W., Xu, Y.X., J. Mater. Sci. Technol. 2167: 34, (2018).

[25] Chen, X., Zhang, Y., Cong, M., Effect of friction stir processing on microstructure and tensile properties of as-cast Mg-8Li-3Al-2Sn (wt.\%) alloy, Vacuum. 175: 109292, (2020).

[26]Sharahi, H.J., Pouranvari, M., Movahedi, M., Strengthening and ductilization mechanisms of friction stir processed cast Mg-Al-Zn alloy, Mat. Sci. and Eng: A, 781: 139429, (2020).

[27] Yang, T., Wang, K., Wang, W., Peng, P., Huang, L., Q1ao, K., Jin, Y., Effect of Friction Stir Processing on Microstructure and Mechanical Properties of AlSi10Mg Aluminum Alloy Produced by Selective Laser Melting, JOM, 71: 1737-1747, (2019).

[28] Maamoun, A. H., Veldhuis, S.C., Elbestawi, M., Friction stir processing of AlSi10Mg parts produced by selective laser melting, J. Mat. Process. Tech. 263: 308-320, (2019).

[29] Moeini, A. H G., Sajadifar, S. V., Engler, T., Heider, B., Neindorf, T., Oechsner, M., Böhm, S., Effect of Friction Stir Processing on Microstructural, Mechanical, and Corrosion Properties of Al-Si12 Additive Manufactured Components, Metals, 10: 85, (2020). 